
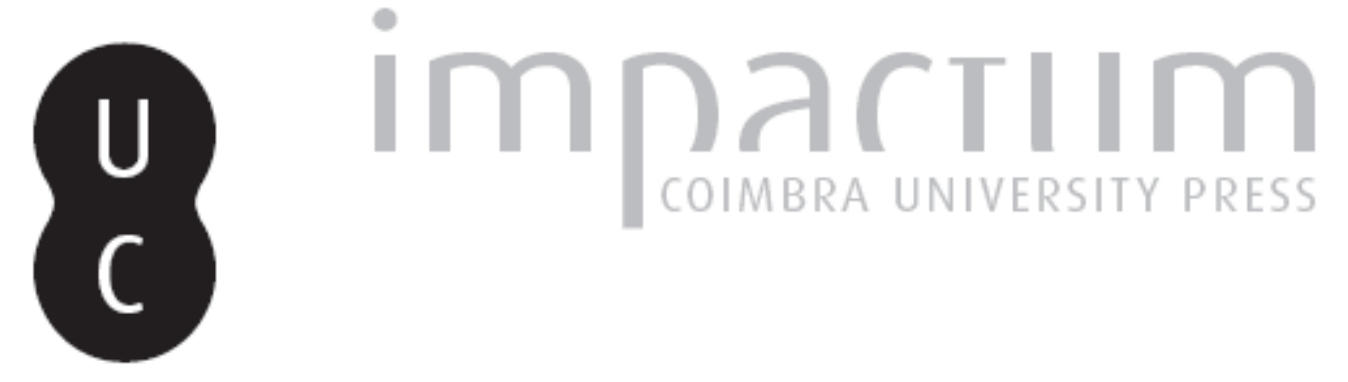

\title{
Avaliação do dano corporal no Brasil: o caso dos acidentes de viação
}

Autor(es): $\quad$ Silva, Wagner; Magalhães, Teresa

Publicado por: Imprensa da Universidade de Coimbra

URL persistente:

URI:http://hdl.handle.net/10316.2/33233

DOI:

DOI:http://dx.doi.org/10.14195/1647-8630_22_5

Accessed : $\quad$ 26-Apr-2023 10:31:18

A navegação consulta e descarregamento dos títulos inseridos nas Bibliotecas Digitais UC Digitalis, UC Pombalina e UC Impactum, pressupõem a aceitação plena e sem reservas dos Termos e Condições de Uso destas Bibliotecas Digitais, disponíveis em https://digitalis.uc.pt/pt-pt/termos.

Conforme exposto nos referidos Termos e Condições de Uso, o descarregamento de títulos de acesso restrito requer uma licença válida de autorização devendo o utilizador aceder ao(s) documento(s) a partir de um endereço de IP da instituição detentora da supramencionada licença.

Ao utilizador é apenas permitido o descarregamento para uso pessoal, pelo que o emprego do(s) título(s) descarregado(s) para outro fim, designadamente comercial, carece de autorização do respetivo autor ou editor da obra.

Na medida em que todas as obras da UC Digitalis se encontram protegidas pelo Código do Direito de Autor e Direitos Conexos e demais legislação aplicável, toda a cópia, parcial ou total, deste documento, nos casos em que é legalmente admitida, deverá conter ou fazer-se acompanhar por este aviso.

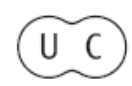




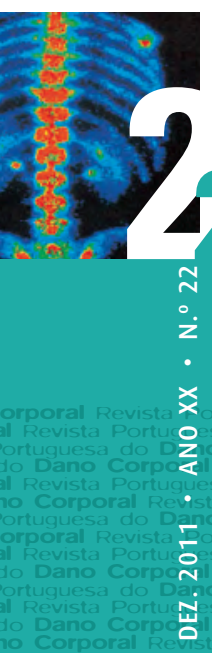

$$
\text { REVISTA PORT U/GUESA }
$$

do
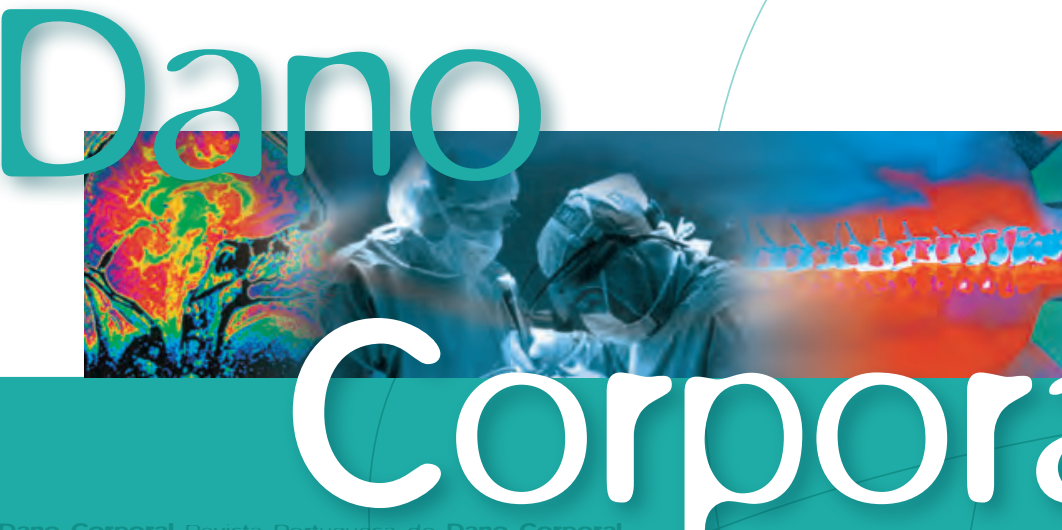

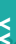

Oesa do Dano Corporal Revista Portuguesa do Dano Corporal

Zo Corporal Revista Portuguesa do Dano Corporal Revista Portuguesa do Dano Corporal

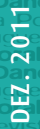

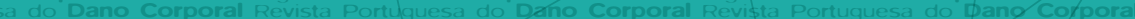

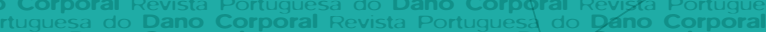

Revista Portuguesa do Dano Corporal Revista Rortuguesa do Dano Corporal
Ro Corporal Revista Portuguesa do Dano Corpgral Revista Portuguesa do Dano Corporal

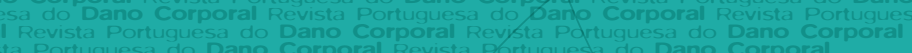




\title{
Avaliação do dano corporal no Brasil. 0 caso dos acidentes de viação
}

\author{
Wagner Silva ${ }^{(1)}$, Teresa Magalhães ${ }^{(2,3,4,5)}$
}

\section{INTRODUÇÀO}

Os acidentes de viação constituem-se, atualmente, como um grave problema de saúde pública e a Organização Mundial de Saúde (OMS) prevê que os seus efeitos irão aumentar se a segurança no trânsito não for adequadamente trabalhada pelos diversos Estados (JORGE \& KOIZUMI, 2007).

De facto, nas últimas décadas do século $\mathrm{XX}$, a entrada dos chamados "países em desenvolvimento" no processo de motorização maciça, fez disparar os números de sinistralidade rodoviária. A combinação de um aumento rápido da frota de veículos, os recursos limitados para a segurança, bem como a manutenção das estradas, produziu verdadeiros estragos, sobretudo em regiões como a África, Ásia e América Latina. Efetivamente, a redução das taxas de sinistralidade observadas nos anos oitenta, em alguns países desenvolvidos, foi insignificante face ao aumento desta sinistralidade nos países em desenvolvimento (ESTEVAN, 2001).

O número oficial de mortos em acidentes de trânsito no Brasil é de cerca de 35.000 por ano, porém, são contados apenas aqueles que morrem no local do acidente, sendo que muitos acreditam que esse número possa ultrapassar os 50.000 (ESTATÍSTICAS DE TRÂNSITO, 2010). Estes representarão, portanto, uma constante preocupação da sociedade dado o alarmante número

1 Instituto Médico-Legal de Belo Horizonte, MG; Departamento de Perícias Médicas do Hospital da Polícia Civil

2 Instituto Nacional de Medicina Legal, I.P.

3 Faculdade de Medicina da Universidade do Porto

4 CENCIFOR - Centro de Ciências Forenses, Portugal

5 Instituto de Ciências Biomédicas "Abel Salazar" da Universidade do Porto 
de vítimas que provocam, apesar do permanente esforço na sua prevenção. As campanhas educativas, a fiscalização rigorosa e o aperfeiçoamento dos aspetos da segurança, tanto nos automóveis como nas vias de condução, são capazes de reduzir os riscos de acidentes, mas não os eliminam. A contínua evolução tecnológica permitiu, contudo, uma melhoria nos diversos níveis de atendimento às vítimas de acidente de viação. Assim, por um lado, vislumbra-se a possibilidade de redução de vítimas mortais mas, por outro, surge o problema do aumento nos custos de assistência médica, de reabilitação e de reintegração dessas vítimas na sociedade.

No que se refere ao atendimento médico das vítimas, desde 1995 que os acidentes de viação constituem a principal causa de internamento de pacientes com lesão medular traumática e com traumatismo crânio-encefálico na rede Brasileira "Sarah" de hospitais de reabilitação, especializada no atendimento de doentes portadores de paralisia cerebral, espinha bífida, traumatismo craniano, acidente vascular cerebral, lesão medular, doenças neuromusculares e problemas ortopédicos, entre outras (REDE SARAH DE HOSPITAIS DE REABILITAÇÃO, 2011).

Entre 1998 e 2005, os acidentes de viação com vítimas passaram de 262.374 para 383.371, segundo registros do DENATRAN (Sistema de Informações do Departamento Nacional de Trânsito) (DENATRAN, 2011). Os tipos de acidente mais frequentes foram as colisões e atropelamentos, embora as suas proporções variassem bastante em determinadas regiões do país. Quanto ao local de ocorrência, prevaleceram sempre as áreas urbanas, e quanto ao período do dia, mais da metade dos eventos ocorreu durante o dia em todas as regiões do Brasil (JORGE \& KOIZUMI, 2007).

No Brasil, o crescente aumento do número de veículos nas últimas décadas, em especial da frota de motocicletas como meio de trabalho (JORGE \& KOIZUMI, 2007), por ser mais ágil e de custo reduzido, é referido como fator que contribui para a manutenção das elevadas taxas de acidentes de viação (OLIVEIRA, 2006).

O panorama em 2005, segundo Jorge e Koizumi (2007), reflete uma taxa de 228 veículos/100 mil habitantes, uma taxa de 208,1 acidentes com vítimas/100 mil habitantes, uma taxa de 19,4 óbitos/100 mil habitantes e uma taxa de internamento hospitalar de 64,1 pacientes/mil habitantes. Os registos hospitalares totalizaram cerca de 160.000 internamentos por ano decorrentes de acidentes de viação (JORGE \& KOIZUMI, 2007).

Os dados relativos ao atendimento hospitalar pelo Sistema Único de Saúde (SUS) indicam cerca de $70 \%$ de hospitalizações das vítimas deste tipo de acidente, tendo em 2005 correspondido a 118.122 vítimas. Esses pacientes foram principalmente do sexo masculino (cerca de $75 \%$ ), com idades entre 
os 30 e os 39 anos, predominando, quanto ao tipo de acidente, os pedestres (JORGE \& KOIZUMI, 2007).

O número de indivíduos com sequelas por acidente de viação tem aumentado significativamente. Entre as explicações para esse fenómeno regista-se: (a) o maior número de acidente de viação entre jovens que apresentam melhores condições de saúde para sobreviver aos traumatismos graves; (b) a maior velocidade dos veículos; (c) o aumento do número de veículos pesados; (d) os avanços nas técnicas médicas de ressuscitação que permitem que doentes que outrora teriam perecido consigam sobreviver (MARIN \& QUEIROZ, 2000).

Assim, os acidentes de viação surgiram como uma epidemia capaz de produzir muitas mortes, ferimentos e sequelas, gerando custos financeiros e sociais enormes (MARIN \& QUEIROZ, 2000), revestindo-se, por isso, de caráter médico-legal e forense, dada a importância do estudo das lesões e sequelas, bem como do estabelecimento do nexo de causalidade entre o traumatismo e aquelas, seja para efeito de atribuição de sanção penal, seja para efeito de indemnização pelo dano corporal resultante.

\section{Aspetos legais da avaliação e reparação do dano corporal pós-traumático em caso de acidente de viação}

A reparação do dano corporal que possa ter lugar em caso de acidente de viação está disciplinada no Código Civil (CC), nos seus artigos $186^{\circ}$ (Aquele que por ação ou omissão voluntária, negligência, ou imprudência, violar direito e causar dano a outrem, ainda que exclusivamente moral, comete ato ilícito) e $927^{\circ}$ (Aquele que, por ato ilícito, causar dano a outrem, fica obrigado a repará-lo)

São pressupostos da responsabilidade civil a existência de uma ação, comissiva ou omissiva, a ilicitude, a culpa, o dano e, ainda, o nexo de causalidade entre o dano e a ação (facto gerador da responsabilidade), pois a responsabilidade civil não poderá existir sem o vínculo entre a ação e o dano (DINIZ, 2002).

A indemnização mede-se pela extensão do dano, segundo o artigo $944^{\circ}$ do CC. Nesta perspetiva, todos os parâmetros de dano corporal medicamente avaliáveis devem ser valorados para uma reparação integral desse dano.

No Código do Processo Civil (CPC), o fundamento para a realização das perícias encontra-se explicitado nos artigos $145^{\circ}$ (Quando a prova do fato depender de conhecimento técnico ou científico, o juiz será assistido por perito, segundo o disposto no artigo 421) e $421^{\circ}$ (O juiz nomeará o perito, fixando de imediato o prazo para entrega do laudo). 
As perícias médico-legais encontram-se, também, disciplinadas através do disposto nos artigos $158^{\circ}$ a $170^{\circ}$ do Capítulo II - Do exame de corpo de delito e das perícias em geral - do Código do Processo Penal (CPP - Decreto-Lei 3639/1941, de 3 de outubro). No Código Penal (CP), as lesões corporais estão referidas num dos dispositivos dos crimes contra a pessoa. Qualquer alteração física ou psíquica decorrente de ação violenta exercida sobre o ser humano, o Estado pune e o objeto da tutela penal é a integridade biopsíquica. Abrange não só o indivíduo, mas a vida e saúde de toda a comunidade.

\section{0 seguro obrigatório de Danos Pessoais causados por Veículos Automotores (DPVAT)}

O Seguro Obrigatório de Danos Pessoais causados por Veículos Automotores (DPVAT) está incluído no rol dos seguros obrigatórios e refere-se ao seguro relativo a danos pessoais causados por veículos automotores de via terrestre, ou por sua carga, a pessoas transportadas ou não. Tem como objetivo indemnizar as vítimas de acidente de viação em caso de invalidez permanente e de despesas médicas e hospitalares, ou os beneficiários das mesmas em caso de morte. A indemnização devida pelo seguro em causa não depende do apuramento de culpa do proprietário ou do condutor do veículo (SANTOS, 2006).

O diploma legal que primeiro introduziu a reparação dos acidentes de viação, independentemente da culpa, foi o Decreto-Lei 73/1966, de 21 de novembro, regulamentado pelo Decreto 61867/1967, de 7 de dezembro. Todos os proprietários de veículos foram obrigados a segurá-los contra os acidentes originados pela sua utilização (RIZZARDO, 1998; MARTINS, 2009).

O seguro obrigatório DPVAT é atualmente disciplinado pela Lei 6194/1974, de 19 de dezembro, alterada pela Lei 8441/1992, de 14 de Agosto, pela Lei 11482/2007, de 31 de maio e, mais recentemente, pela Lei 11945/2009, de 4 de junho, onde são descritos os critérios de indemnização e as instituições que devem realizar as avaliações dos danos pessoais sofridos (SANTOS, 2006; MARTINS, 2009).

Mas foi com a Lei 6194/1974, de 19 de dezembro, que se tornou num seguro de danos simplesmente pessoais, descaracterizando aquele seguro de responsabilidade civil; ou seja, passou a ser como um seguro obrigatório de danos pessoais, independente do apuramento de culpa (MARTINS, 2009).

Tratando-se de um seguro que tem por objetivo cobrir os danos pessoais causados pelo veículo, exige-se, naturalmente, a verificação do nexo de causalidade entre o dano e o acidente (SANTOS, 2006; MARTINS, 2009). Por outro lado, não sendo necessário demonstrar a atitude culposa, ou até dolosa, do causador do acidente, bastando simplesmente demonstrar o nexo de causalidade entre o sinistro de viação e dano sofrido, resulta claro que o seguro 
visa ressarcir o prejuízo de forma rápida, sem se enveredar em protelatórias discussões jurídicas (MARTINS, 2009). A referência à necessidade de apenas comprovar o acidente e o dano pessoal dele decorrente encontra-se no artigo $5^{\circ}$ da Lei 6194/1974, de 19 de dezembro, uma vez que a indemnização será efetuada independentemente do apuramento de culpa.

Uma alteração importante no seguro aconteceu com a Lei 11945/2009, de 4 de junho, que introduziu uma nova tabela, mais reduzida que a versão de 1974, estabelecendo uma série de taxas que devem ser observadas para a fixação da indemnização devida em caso de invalidez permanente, além de disposições orientadoras quanto à utilização desta tabela e outras orientações.

Os danos pessoais cobertos pelo seguro compreendem as indemnizações por morte, por invalidez permanente, total ou parcial, e por despesas de assistência médica e suplementares, por pessoa vitimada, conforme disposto no artigo $3^{\circ}$ da Lei 6194/1974, de 19 de Dezembro. Na hipótese de invalidez permanente, a indemnização depende do grau de invalidez que a vítima apresentar (MARTINS, 2009).

Note-se que as disposições legais do seguro DPVAT referem apenas regras e orientações gerais para indemnizações pelos danos pessoais decorrentes do acidente, não definido as normas periciais quanto à metodologia de avaliação médico-legal destes danos.

\section{Avaliação médico-legal e perícia médica}

As perícias para efeito de atribuição de indemnização por acidente de viação podem ser realizadas nos Institutos Médico-Legais (IML) ou nos tribunais; raramente são efetuadas nas companhias de seguros.

Aos IML são remetidos, através do Delegado de Polícia, todos os casos de acidentes viação tendo em vista avaliar o dano para efeitos de indemnização pelo DPVAT. Efetivamente, conforme nova redação dada ao parágrafo $5^{\circ}$, do artigo $5^{\circ}$, da Lei 6194/1974, de 19 de dezembro, estabelece-se que as avaliações periciais das vítimas de acidentes de viação, para fins deste seguro, serão realizadas pelos IML: O Instituto Médico Legal da jurisdição do acidente ou da residência da vítima deverá fornecer, no prazo de até 90 (noventa) dias, laudo à vítima com a verificação da existência e quantificação das lesões permanentes, totais ou parciais.

As perícias daqui resultantes são remetidas à Delegacia de Polícia (que pode usar este relatório também para efeitos penais), com uma cópia para a vítima que a encaminhará para a entidade seguradora.

No entanto, muitos destes casos, para os quais não é possível estabelecer um acordo entre o sinistrado e a seguradora, seguem para os Tribunais Cíveis. 
Nestas situações pode ter lugar uma nova perícia, a qual é realizada por um perito privado nomeado pelo Juiz, com base em critérios de confiança. Podem, ainda, as partes, apresentar os seus relatórios periciais, os quais são elaborados por peritos privados contratados para o efeito.

Os IML no Brasil estão subordinados, na maioria dos Estados, às Secretarias de Segurança Pública, encarregadas das ações policiais. Desta maneira, as lesões decorrentes dos acidentes de viação para indemnização pelo DPVAT são sempre analisadas como se fossem dolosas, à semelhança das agressões físicas.

De facto, não existe uma norma específica para avaliação destes danos em sede de Direito Civil, com parâmetros de dano definidos, seguindo-se antes o modelo do Direito Penal, apesar de estes dois ramos do Direito terem objetivos distintos.

Assim, as perícias médico-legais realizadas nos IML obedecem a uma metodologia de exame e elaboração do relatório pericial direcionada para resposta aos quesitos oficiais relacionados com lesões corporais prevista no artigo $129^{\circ}$ do CP, não se fazendo referência a quantificações e valorações dos diversos parâmetros de dano corporal que, noutros países, e para estes casos, se enquadram na metodologia de avaliação do dano corporal em Direito Civil (MAGALHÃES \& VIEIRA, 2010).

Deste modo, de acordo com o CP, descreve-se o dano corporal resultante, tendo em conta os seguintes grupos de gravidade do mesmo (FRAGOSO, 1976): (a) Lesões corporais leves ou simples: aquelas que não causam os resultados previstos no artigo $129^{\circ}$ do $\mathrm{CP}$, parágrafos $1^{\circ} .2^{\circ}$ e $3^{\circ}$. O crime exige sempre que a lesão atinja um mínimo indispensável a constituir verdadeiramente um dano à integridade corporal ou à saúde; (b) Lesões corporais graves: previstas no parágrafo $1^{\circ}$ do artigo $129^{\circ}$ do $\mathrm{CP}$, verificam-se quando da ofensa resultam incapacidade para as ocupações habituais por mais de 30 dias, perigo de morte, debilidade permanente de membro, sentido ou função, ou aceleração de parto; (c) Lesões corporais gravíssimas: são as lesões descritas no parágrafo $2^{\circ}$ do artigo $129^{\circ}$ do $\mathrm{CP}$, podendo verificar-se nos casos de incapacidade permanente para o trabalho, enfermidade incurável, perda ou inutilização de membro, sentido ou função, deformidade permanente ou aborto.

Quando o primeiro exame de lesões corporais não for conclusivo quanto à qualificação das lesões acima descritas, são realizados "exames complementares de lesão corporal”, conforme determina o artigo $168^{\circ}$ do CPP. Portanto, para todos os casos de lesão corporal, cujo primeiro exame tiver sido incompleto, será necessário um “exame complementar de lesão corporal”.

De acordo com o artigo $3^{\circ}$ da Lei 6194/1974, de 19 de dezembro, a valoração médico-legal da invalidez permanente dos acidentes de viação deve 
seguir o disposto no parágrafo $1^{\circ}$, o qual refere que as lesões diretamente decorrentes do acidente, deverão ser enquadradas na tabela anexa a esta Lei, deixando claro que deve ser comprovado o nexo de causalidade médica entre o dano pessoal e o acidente. Refere-se, ainda, nesse diploma, que as lesões serão caracterizadas como permanentes desde que não sejam suscetíveis de melhoria proporcionada por qualquer medida terapêutica, quer dizer, a partir de sua consolidação médico-legal. No final do parágrafo é feita referência à classificação que deve ser dada à invalidez permanente, aspeto que será objeto de análise mais adiante. Os incisos I, II e III que se seguem ao artigo $3^{\circ}$ da Lei 6194/1974, de 19 de dezembro, referem-se aos valores a serem pagos em caso de morte (inciso I), invalidez permanente (inciso II) e reembolso à vítima (inciso III), no caso de despesas de assistência médica e suplementares devidamente comprovadas.

Na sequência do parágrafo $1^{\circ}$ do artigo $3^{\circ}$ da Lei 6194/1974, de 19 de dezembro, os incisos I e II estabelecem as demais regras a serem observadas na valoração médico-legal da invalidez permanente observada, bem como a sua relação com o valor da indemnização a ser estabelecida: (I) Quando se tratar de invalidez permanente parcial completa, a perda anatômica ou funcional será diretamente enquadrada em um dos segmentos orgânicos ou corporais previstos na tabela anexa, correspondendo a indenização ao valor resultante da aplicação do percentual ali estabelecido ao valor máximo da cobertura; (II) Quando se tratar de invalidez permanente parcial incompleta será efetuado o enquadramento da perda anatômica ou funcional na forma prevista no inciso I deste parágrafo, procedendo-se, em seguida, à redução proporcional da indenização que corresponderá a 75\% (setenta e cinco por cento) para as perdas de repercussão intensa, 50\% (cinquenta por cento) para as de média repercussão, $25 \%$ (vinte e cinco por cento) para as de leve repercussão, adotando-se ainda o percentual de $10 \%$ (dez por cento), nos casos de sequelas residuais.

Neste sentido, serão indemnizadas as sequelas de acordo com o grau de afetação permanente da integridade psicofísica observada, subdivididas em total ou parcial, completa ou incompleta. Na tabela constam itens, com valores percentuais, para uma invalidez permanente total ou parcial. Ou seja, a nova configuração de invalidez permanente, na tabela DPVAT, pode ser total ou parcial, sendo esta, ainda, dividida em completa e incompleta. Se a invalidez for incompleta, será efetuado um enquadramento com uma percentagem proporcional, que corresponde a 75\% para sequelas com repercussão intensa, 50\% quando a repercussão é moderada e $25 \%$ para uma repercussão leve. Adotou-se, ainda, uma percentagem de $10 \%$ para sequelas residuais. $\mathrm{O}$ enquadramento dessas perdas na tabela de danos pessoais indica o grau de invalidez e a percentagem aplicável ao valor de cobertura (MARTINS, 2009). 
A utilização da tabela de quantificação dos danos para determinar valores de indemnização para invalidez não é algo novo no universo de perícias das seguradoras. Os seguros pessoais já se valem deste recurso, e a Superintendência de Seguros Privados (SUSEP) possui uma tabela para cálculo de indemnização em caso de invalidez permanente decorrente de acidentes pessoais, conforme Circular SUSEP 29/1991, de 29 de dezembro.

Esta tabela foi utilizada como referência para a valoração médico-legal das sequelas decorrentes de acidentes de viação até muito recentemente, quando uma nova tabela foi incluída no artigo $3^{\circ}$ da Lei 6194/1974, de 19 de dezembro, através da Lei 11945/2009, de 4 de junho. Trata-se de uma tabela reduzida, cujo objetivo, ao que parece, foi o de simplificar o enquadramento das lesões para fins de indemnização.

No entanto, e apesar do consignado na lei, esta metodologia de avaliação dos danos permanentes, ainda que mais adequada aos propósitos do Direito Civil, não é seguida na grande parte dos IML do Brasil.

Já no que à perícia médica efetuada por médicos privados, para os tribunais, seguradoras e sinistrados diz respeito, esta tabela será também pouca vezes utilizada, não existindo, contudo, entre estes peritos, uma metodologia harmonizada de avaliação do dano corporal pós-traumático para efeito da reparação das vítimas, pelo que o modelo de avaliação pericial fica ao critério de cada um.

Do anteriormente exposto, decorre que o relatório pericial efetuado pela maioria dos IML é naturalmente muito simples, incluindo sobretudo uma nota sobre o histórico e a resposta aos quesitos oficiais.

Também no que às perícias privadas diz respeito, não existe um modelo de relatório pericial a ser seguido pelos profissionais, motivo pelo qual cada perito define o seu modelo, não sendo raro o relatório que se limita a responder aos quesitos apresentados pelo juiz e pelas partes envolvidas.

Existem, no entanto, alguns peritos médicos que começam a utilizar o modelo português, o qual se identifica com o modelo europeu, no âmbito do Direito Civil (MAGALHÃES \& VIEIRA, 2010). Estas perícias têm sido muito bem recebidas pelos tribunais, havendo referência a que essa metodologia proporciona uma melhor descrição e organização dos parâmetros de dano corporal nos relatórios. Também a nível dos peritos que tomam conhecimento do modelo de relatório com a descrição dos diversos parâmetros de dano corporal no capítulo da Discussão e no das Conclusões, existe uma boa aceitação do mesmo e até algum entusiasmo com esta possibilidade, motivo pelo qual vários médicos têm realizado o Curso de Pós-Graduação em Avaliação do Dano Corporal Pós-Traumático em Portugal, tendo já tido lugar um destes cursos, realizado pelo Instituto Nacional de Medicina Legal, I.P., daquele país, em Belo Horizonte. 


\section{Objetivos}

Com o aumento do número e da gravidade dos acidentes de viação têm-se ampliado as discussões doutrinárias relacionadas com a avaliação médico-legal no contexto da reparação do dano corporal Direito Civil (OLIVEIRA SÁ, 1992), tendo-se evoluído largamente nesta matéria, nos últimos anos, designadamente na Europa. Neste sentido, vem-se observando, por parte dos peritos médicos, um crescente interesse no estabelecimento de parâmetros técnicos para a qualificação e quantificação do dano corporal. Contudo, como já referido, no Brasil não estão oficialmente definidas normas periciais quanto a esta metodologia de avaliação e as que existem não são cumpridas, o que admite a ocorrência de desigualdades no tratamento de vítimas com danos semelhantes, daí resultando, necessariamente, prejuízos na boa administração da justiça. Assim, o presente estudo tem como objetivo geral analisar do ponto de vista médico-legal e forense a metodologia de avaliação do dano corporal em vítimas de acidentes de viação no Brasil para, a partir dos resultados obtidos, refletir sobre os procedimentos adotados em termos desta metodologia, tendo como elementos de comparação o modelo seguido em Portugal, largamente validado neste âmbito.

\section{MATERIAL E MÉTODOS}

\section{Material}

Analisaram-se os relatórios relativos às avaliações periciais realizadas em vítimas de acidente de viação encaminhadas para o IML de Belo Horizonte, Minas Gerais, durante o ano de 2010. Foram selecionados os relatórios que obedeciam aos seguintes critérios de inclusão ( $n=254)$ : (a) Relatórios elaborados no IML de Belo Horizonte; (b) Durante o ano de 2010; (c) Relativos a acidentes de viação; (d) Independentemente do sexo e idade da vítima; (e) Em que havia consolidação médico-legal das lesões; (f) Encontrando-se concluídos e já remetidos à entidade solicitante.

\section{Métodos}

Foi realizado um estudo observacional, com componente analítico, que consistiu numa análise dos relatórios médico-legais acima referidos, elaborados no âmbito da avaliação do dano corporal pós-traumático por acidentes de viação. Para tal foi utilizada uma ficha de colheita de dados, expressamente 
construída para o efeito, a qual reúne dados relativos às vítimas, ao tipo de acidente, às lesões e sequelas sofridas e aos parâmetros de dano corporal avaliados. Esta ficha baseou-se no modelo de avaliação médico-legal do dano corporal em Direito Civil, em vigor no Instituto Nacional de Medicina Legal, I.P., de Portugal (MAGALHÃES \& VIEIRA, 2010).

Os dados foram sempre colhidos pelo investigador, para garantir a fiabilidade dessa mesma colheita e foram tratados no programa Microsoft Excel 2007 e no programa estatístico IBM.SPSS Statistics versão 19. Foi efetuada uma estatística descritiva, com recurso a tabelas e gráficos, considerando-se para a elaboração dos mesmos apenas os casos cuja informação alvo de avaliação constava do relatório pericial, pelo que o número dos casos analisados varia muito entre as diversas análises.

\section{RESULTADOS}

\section{Caracterização das vítimas}

As vítimas eram maioritariamente do género masculino $(70.3 \%)$ e tinham uma idade média de 42 anos ( $\mathrm{SD}=15$ anos; Min.=9 anos; Máx.=83 anos). As mulheres apresentaram idade média mais alta que os homens (48 anos contra 39 anos), sendo esta diferença observada estatisticamente significativa $(\mathrm{p}<0.001$ para um valor de referência de $\mathrm{p}<0.05)$. O gráfico 1 apresenta a dispersão da idade das vítimas por faixa etária, notando-se que $46.4 \%$ estão na faixa etária entre 21 e 40 anos de idade. Note-se que em 8 casos não havia indicação quanto à idade da vítima (3.1\%). A distribuição, quanto ao estado civil, revela que a maioria $(47.6 \%)$ era casada (Tabela 1$)$, sendo que em $8.3 \%(\mathrm{n}=21)$ dos casos esta informação não constava do relatório médico-legal. Quanto ao local de residência, a maioria das vítimas residia em Belo Horizonte (66\%) (Gráfico 2).

Em nenhum relatório pericial é feita qualquer referência aos antecedentes pessoais da vítima, sejam patológicos ou traumáticos. 
Gráfico 1 - Distribuição da idade dos entrevistados por faixa etária $(n=246)$

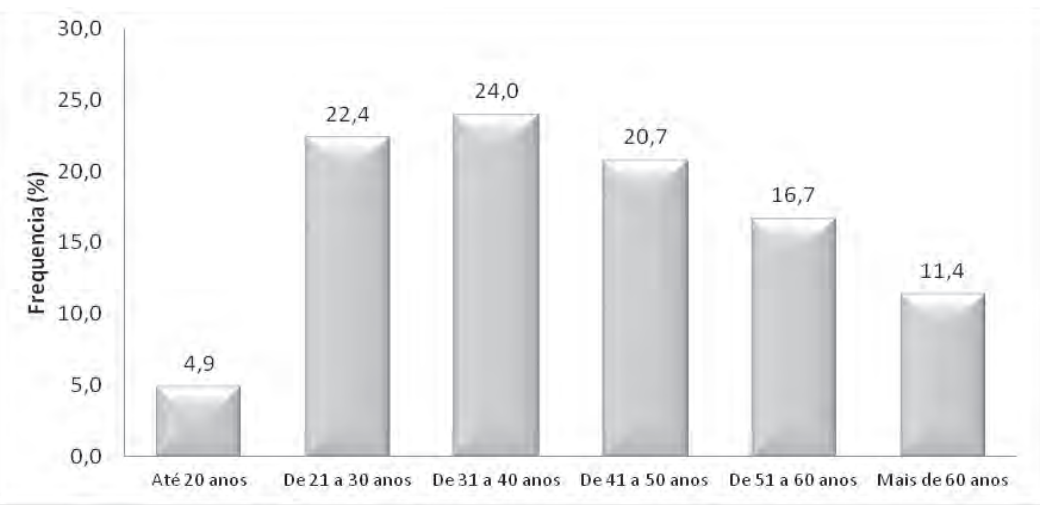

Tabela 1 - Distribuição das vítimas por estado civil $(\mathrm{n}=233)$

\begin{tabular}{lcc}
\cline { 2 - 3 } & $\mathrm{n}$ & $\%$ \\
\hline Casado(a) & 111 & 47.6 \\
Solteiro(a) & 94 & 40.3 \\
Divorciado(a) & 10 & 4.3 \\
Viúvo(a) & 8 & 3.4 \\
Separado(a) & 7 & 3.0 \\
União de facto & 3 & 1.3 \\
\hline
\end{tabular}

Gráfico 2 - Distribuição dos Entrevistados por local de residência (n=254)

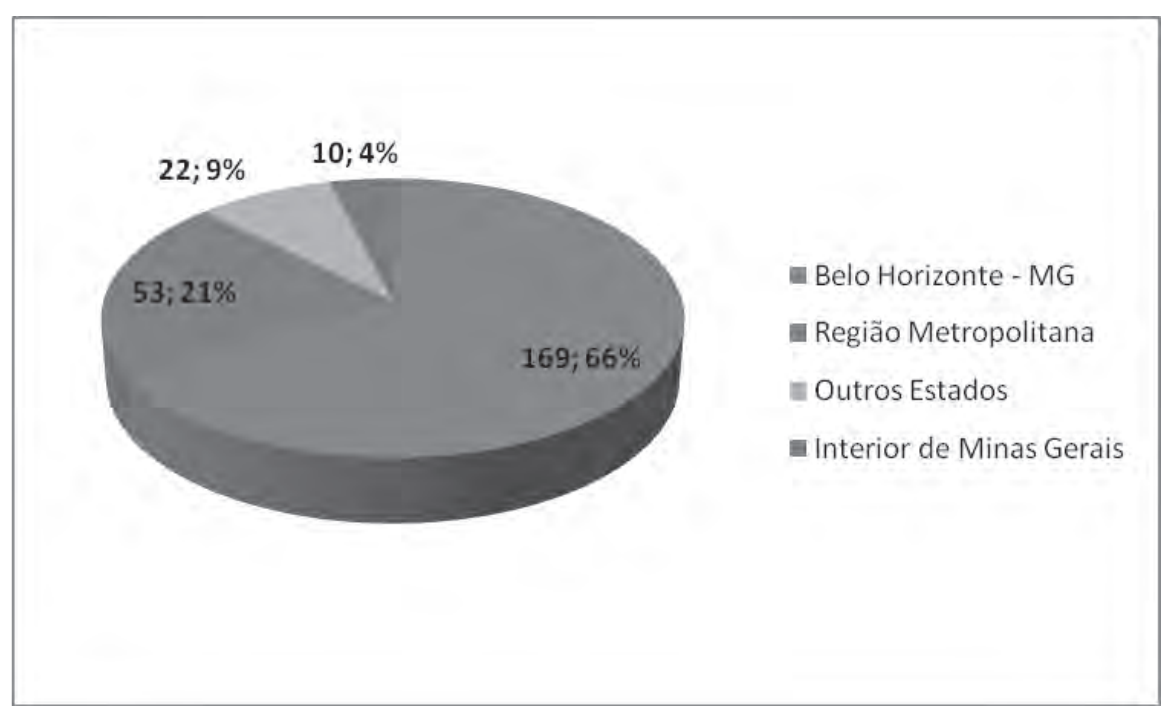




\section{Caracterização do acidente}

A data do acidente não consta nos relatórios em $86.6 \%$ dos casos.

Em relação ao tipo de acidente, verificou-se que em $81.9 \%$ dos casos a sua caracterização também não consta no relatório $(n=208)$. Nos casos em que existia tal informação $(\mathrm{n}=46)$, o atropelamento foi o tipo de acidente mais frequente $(80.4 \%)$ (Tabela 2). Em nenhum dos relatórios foi feita menção à localização da vítima no veículo ou à utilização de medidas de segurança, como o cinto de segurança, por exemplo.

Tabela 2 - Tipo de acidente $(n=46)$

\begin{tabular}{lcc}
\cline { 2 - 3 } & $\mathrm{n}$ & $\%$ \\
\hline Atropelamento por viatura & 37 & 80.4 \\
Outro & 5 & 10.9 \\
Colisão entre veículos em andamento & 2 & 4.3 \\
Capotamento & 1 & 2.2 \\
Despiste & 1 & 2.2 \\
\hline
\end{tabular}

Relativamente ao veículo envolvido no acidente, esta informação não constava no relatório em $68.5 \%$ dos casos $(n=174)$. Nos casos em que existia tal informação $(\mathrm{n}=80)$, em $45 \%$ referia-se que a vítima seguia em veículo de 4 rodas e que em $46.2 \%$ dos casos era peão, não se indicando, neste caso, o tipo de veículo atropelante (Tabela 3).

Tabela 3 - Veículo envolvido $(n=80)$

\begin{tabular}{lcc}
\cline { 2 - 3 } & $\mathrm{n}$ & $\%$ \\
\hline Peão & 37 & 46.2 \\
Em veículo motorizado de 2 rodas & 36 & 45.0 \\
Em camião/camioneta & 4 & 5.0 \\
Em veículo motorizado de 4 rodas & 2 & 2.5 \\
Outros & 1 & 1.3 \\
\hline
\end{tabular}

\section{Caracterização das lesões iniciais}

Em 52 dos relatórios médico-legais (20.5\%), as lesões resultantes do acidente não estavam descritas relativamente à sua localização nos segmentos corporais. Em nenhum caso foi negada a sua existência. Nos casos em que existia esta descrição, e tendo em conta que as regiões atingidas podem ser múltiplas $(\mathrm{n}=260)$, os membros inferiores foram a região mais atingida (50.4\%), seguida dos membros superiores (23.8\%) (Tabela 4). 
Tabela 4 - Distribuição das lesões por localização no corpo $(\mathbf{n = 2 6 0})$

\begin{tabular}{lcc}
\cline { 2 - 3 } & $\mathrm{n}$ & $\%$ \\
\hline Membros inferiores & 131 & 50.4 \\
Membros superiores & 62 & 23.8 \\
Crânio e pescoço & 26 & 10.0 \\
Face & 15 & 5.8 \\
Pelve e períneo & 7 & 2.7 \\
Ráquis e medula & 6 & 2.3 \\
Abdómen & 5 & 2.0 \\
Tórax & 5 & 2.0 \\
Outros & 3 & 1.2 \\
\hline
\end{tabular}

Também não foi registado nos relatórios o tipo de lesão em 31.9\% dos casos $(n=81)$. Em nenhum caso foi negada a sua existência. Nos casos em que existia esta descrição, os quais também podem incluir múltiplos tipos de lesões $(n=296)$, verificou-se que as lesões mais frequentes foram as fraturas (49.7\%) (Tabela 5).

Tabela 5 - Distribuição do tipo de lesões $(n=296)$

\begin{tabular}{lcc}
\cline { 2 - 3 } & $\mathrm{n}$ & $\%$ \\
\hline Farturas & 147 & 49.7 \\
Contusões órgãos internos & 23 & 7.8 \\
Outra & 15 & 5.1 \\
Lacerações tecidos moles & 12 & 4.1 \\
Contusões/escoriações etc. dos tecidos moles & 7 & 2.4 \\
Amputações & 6 & 2.0 \\
Lacerações órgãos internos & 5 & 1.7 \\
\hline
\end{tabular}

\section{Caracterização das sequelas}

Em 3.1\% do total dos relatórios, as sequelas não se encontravam aí descritas $(\mathrm{n}=8)$. Em 12.9\% do total dos casos era feita referência expressa à ausência de sequelas. Nos casos em que estas sequelas existiam e a sua descrição estava disponível $(n=279)$, verificou-se que as sequelas a nível do corpo mais frequentes (que podem ser múltiplas) foram nos membros inferiores $(48 \%)$ e superiores $(22.6 \%)$ (Tabela 6$)$. 
Tabela 6 - Distribuição das sequelas no corpo $(n=279)$

\begin{tabular}{lcc}
\cline { 2 - 3 } & $\mathbf{n}$ & $\%$ \\
\hline Membros Inferiores & 134 & 48.0 \\
Membros Superiores & 63 & 22.6 \\
Sem sequelas & 36 & 12.9 \\
Crânio e Pescoço & 21 & 7.5 \\
Outra & 9 & 3.2 \\
Face & 6 & 2.2 \\
Ráquis e Medula & 5 & 1.8 \\
Pelve e Períneo & 3 & 1.1 \\
Abdómen & 2 & 0.7 \\
\hline
\end{tabular}

Quanto às sequelas funcionais, em $9.1 \%$ do total dos relatórios médico-legais, esta informação não constava $(n=23)$, sendo que em 36 casos estas sequelas são expressamente negadas nos relatórios (14.2\%). Nos casos em que estas sequelas existiam e a sua referência foi feita no relatório $(n=283)$, a sequela mais frequente foi a nível da marcha e postura (48.8\%) (Tabela 7).

Tabela 7 - Distribuição das sequelas funcionais $(\mathrm{n}=247)$

\begin{tabular}{lcc}
\cline { 2 - 3 } & n & $\%$ \\
\hline Marcha e postura & 138 & 55.9 \\
Manipulação e preensão & 60 & 24.3 \\
Outra & 20 & 8.1 \\
Cognição e afetividade & 14 & 5.7 \\
Controlo dos esfíncteres & 9 & 3.6 \\
Sexualidade e procriação & 6 & 2.4 \\
\hline
\end{tabular}

As sequelas situacionais não constavam em $79.5 \%$ do total dos relatórios $(n=202)$, sendo negadas em 35 casos $(13.8 \%)$. Dos casos em que estas sequelas existiam e a sua referência era feita no relatório $(n=26)$, a mais frequente foi relativa às atividades da vida diária $(50 \%)$.

Tabela 8 - Distribuição das sequelas situacionais $(\mathbf{n}=26)$

\begin{tabular}{lcc}
\cline { 2 - 3 } & $\mathrm{n}$ & $\%$ \\
\hline Atividades da vida diária & 13 & $\mathbf{5 0 . 0}$ \\
Vida afetiva e social & 6 & 23.1 \\
Vida profissional & 6 & 23.1 \\
Outra & 1 & 3.8 \\
\hline
\end{tabular}

Relativamente a uma eventual alteração significativa da vida anterior, não constavam informações no relatório em $82.3 \%$ dos casos $(n=209)$. Nos 
casos em que existia referência a este aspeto $(n=45)$ não se terão verificado consequências relevantes em 88.9\% (Tabela 9).

Tabela 9 - Situação de vida após o acidente $(n=45)$

\begin{tabular}{lcc}
\cline { 2 - 3 } & $\mathrm{n}$ & $\%$ \\
\hline Não houve alteração significativa da sua vida anterior & 40 & 88.9 \\
Ficou sem autonomia & 3 & 6.7 \\
Foi reformado(a) & 2 & 4.4 \\
\hline
\end{tabular}

\section{Caracterização dos parâmetros de dano}

As referências ao nexo de causalidade, à data de consolidação médico-legal das lesões e aos parâmetros de dano temporários não constavam de nenhum dos relatórios analisados.

Em relação aos parâmetros de dano permanentes, também não constavam do relatório numa elevadíssima percentagem de casos $(93.3 \%, \mathrm{n}=237)$. A menção aos parâmetros de dano corporal era mais frequente relativamente ao Dano Estético, ainda que assim mesmo este tenha sido avaliado em apenas 9 casos; os restantes danos foram, também, residualmente avaliados (Tabela 10).

Tabela 10 - Danos permanentes $(n=21)$

\begin{tabular}{lcc} 
& $\mathrm{n}$ & $\%$ \\
\hline Dano Estético & 9 & 42.9 \\
Incapacidade absoluta geral & 4 & 19.0 \\
Rebate profissional & 4 & 19.0 \\
Dano Sexual & 2 & 9.5 \\
Incapacidade parcial geral & 1 & 4.8 \\
Dano Futuro & 1 & 4.8 \\
\hline
\end{tabular}

No que se refere às dependências, em $84.3 \%(n=214)$ dos relatórios não constavam informações sobre este aspeto, sendo estas expressamente negadas em 7 casos (2.6\%). Em alguns casos eram descritas dependências múltiplas, revelando-se como mais frequentes as ajudas técnicas (58.7\%) (Tabela 11).

Tabela 11 - Dependências $(n=46)$

\begin{tabular}{lcc} 
& $\mathrm{n}$ & $\%$ \\
\hline Ajudas técnicas & 27 & 58.7 \\
Ajudas medicamentosas & 7 & 15.2 \\
Tratamento médico regular & 6 & 13.0 \\
Terceira pessoa & 5 & 10.9 \\
Outra & 1 & 2.2 \\
\hline
\end{tabular}




\section{DISCUSSÃO}

O presente estudo permitiu confirmar a ideia de que a ausência de uma metodologia específica para a realização dos exames e relatórios periciais em caso de acidente de viação e tendo em vista a indemnização do dano corporal, promove a realização de relatórios muito rudimentares, baseados sobretudo no modelo penal, e valorizando, particularmente, a resposta aos quesitos.

Esta atitude não é nova. Em Portugal - país cuja referência seguimos para orientar este estudo - anteriormente a 1990, a maior parte dos exames em Direito Civil, elaborados nos três Institutos de Medicina Legal então existentes, eram muito vagos, seguindo-se por vezes o modelo penal para descrição das lesões e usando-se a Tabela de Incapacidades para Acidentes de Trabalho e Doenças Profissionais para avaliar a chamada "IPP"; privilegiava-se a resposta aos quesitos.

O ano de 1990 é um ano de referência porque foi nessa ocasião que o Professor Oliveira Sá, então diretor do Instituto de Medicina Legal de Coimbra, deu início ao $1^{\circ}$ Curso de Pós-Graduação em Avaliação do Dano Corporal Pós-Traumático em Direito Civil, publicando em 1992 o primeiro livro português neste âmbito (OLIVEIRA SÁ, 1992). Este Curso, iria lançar as bases de toda a mudança que se começou a operar e que foi consolidada pela criação do Instituto Nacional de Medicina Legal, em 2000, o qual veio promover a harmonização da atividade pericial.

Mas, apesar de não existirem normas para os exames realizados em sede de Direito Civil no Brasil, existem algumas no que se refere à avaliação do dano corporal para efeitos de indemnização, e a que importa atender: (a) $\mathrm{O}$ artigo $944^{\circ}$ do CC, refere que a indemnização se mede pela extensão do dano, o que pressupõe a descrição e medida do mesmo, nos seus diversos aspetos; (b) A referência à necessidade de fazer a prova do dano resultante está também plasmada no artigo $5^{\circ}$ da Lei 6194/1974, de 19 de Dezembro; (c) O DPVAT (Lei 11945/2009, de 4 de junho) exige a avaliação do nexo de causalidade; (d) No artigo $3^{\circ}$ da Lei acima referida indica-se a Tabela de invalidez permanente a ser usada nestes casos.

Estas normas não são, contudo, tidas em conta na maioria dos casos, o que põe em causa o valor da perícia e prejudica, portanto, a atribuição da justa reparação da vítima.

Assim, para analisar a situação brasileira, passível de ser descrita através da análise do que, nesta matéria, é a metodologia seguida no IML de Belo Horizonte, iremos de seguida analisar os resultados deste trabalho considerando os aspetos constantes da ficha de colheita de dados, passo a passo. 


\section{Vítimas, acidentes, lesões e sequelas}

Os resultados relativos à caracterização das vítimas, acidentes, lesões e sequelas são os expetáveis para a sinistralidade rodoviária e, na generalidade, estão de acordo com o descrito na literatura sobre estes acidentes quando ao género das vítimas (masculino) e sua idade (adultos jovens), bem como ao tipo de lesões e sequelas resultantes, e sua localização (contusão tecidos moles e fraturas, preferencialmente nos membros) (MAGALHÃES T e col, 1998; KHAN ZU e col, 2010). Apenas não se verifica concordância quanto ao mecanismo do acidente que, sendo mais frequentemente a colisão em viaturas, no caso presente foi o atropelamento. No entanto, tal como já referido, no Brasil as taxas de colisões e atropelamentos (os dois tipos de acidente mais frequentes), variam muito (JORGE \& KOISUMI, 2007).

Mas não nos iremos deter nesta análise, dado que o objetivo do estudo se prende com a metodologia da perícia, propriamente dita, pelo que voltaremos à análise destes pontos mas, agora, na perspetiva da perícia médico-legal.

\section{A avaliação do dano corporal}

O dano corporal pode ser definido como qualquer alteração ou perturbação da integridade física ou psíquica, com caráter económico, moral, familiar, penal, laboral, entre outros (CUETO, 2001). A avaliação médico-legal do dano corporal constitui, na prática, um conceito multidisciplinar, cujo objetivo final é a atribuição de uma indemnização, geralmente económica.Os elementos que integram esta avaliação, no sentido de delimitar suas fronteiras, são (BOROBIA, 2006): (a) A pessoa que sofreu uma alteração mais ou menos brusca na sua integridade psicofísica, existindo um responsável ou uma situação de risco que a determinou; (b) A compensação ou ajuda que esta pessoa poderá ter direito, seja por uma alteração temporária ou permanente na integridade psicofísica; (c) A quantificação prévia da alteração da saúde previamente ao cálculo da indemnização, comparando-se o estado de saúde atual com o que existia antes da modificação; (d) A reparação que se estabelece por meio de normas legais e, por vezes, jurídicas.

Como refere França (2004), autoridade brasileira nesta matéria, no Brasil, o objetivo fundamental do estudo médico-pericial das lesões corporais é a catacterização da sua extensão, gravidade e perenidade, ou seja, sua quantidade e qualidade; são estas que traduzem grande parte do dano corporal, e que o explicam. Assim, a avaliação do dano corporal, que faz recurso a um relatório escrito e o objetivo relativo ao exame pericial efetuado, deve promover a correta descrição e análise do evento e da vivência do dano, dos elementos de dano temporários e permanentes, a ponderação do nexo de 
causalidade, bem como da data de cura ou consolidação das lesões, para posterior avaliação dos diversos parâmetros de dano na pessoa, em função do enquadramento legal da perícia (MAGALHÃES e col., 2010).

\section{Descrição do traumatismo e do dano resultante}

Relativamente aos relatórios médico-legais analisados, verifica-se que os dados que nos permitem caraterizar todo o evento (desde aspetos da vítima, a aspetos do traumatismo e lesões resultantes), são muito omissos, não permitindo, assim, aquela necessária caraterização.

Aspetos tão simples como a idade e estado civil da vítima, falham em 3.1\% e $8.3 \%$ dos relatórios,respetivamente, e a descrição dos seus antecedentes pessoais patológicos e traumáticos, nunca é feita. A análise das profissões não foi considerada neste estudo pois, além de omissa, na maior parte dos casos, a designação das mesmas variava tanto que se entendeu não serem esses dados passíveis de análise.

Também no que à caracterização do acidente diz respeito, esta não se concretiza em $81.9 \%$ dos casos; poucos são os relatórios que descrevem o veículo envolvido, assim como o tipo de acidente verificado.

Alguns são também omissos quanto à descrição da localização e tipo de lesões (20.5\% e $31.9 \%$, respetivamente), bem como à descrição das sequelas, raramente as considerando na sua perspetiva tridimensional: as sequelas corporais, funcionais e situacionais não são referidas em 3.1\%, 9.1\% e 79.5\% dos relatórios, respetivamente.

Ora, como adiante se irá referir, estes aspetos são fundamentais para o estabelecimento do nexo de causalidade entre o traumatismo e o dano (VIEIRA \& CORTE-REAL, 2008).

Constatou-se, ainda, que a maior parte dos relatórios (86.6\%) não referem a data do acidente, prejudicando a determinação de uma data de consolidação e, consequentemente, a análise dos danos temporários.

Face a estas constatações, importará referir as "Recomendações Gerais para a Realização de Relatórios Periciais de Clínica Forense Relativos ao Dano Pós-Traumático" do Instituto Nacional de Medicina Legal, I.P., de Portugal (MAGALHÃES e col, 2010), as quais tiveram em conta, para a sua elaboração, a literatura e boas práticas sobre a matéria.Nelas se refere que os peritos, na elaboração de um relatório pericial, devem atender à descrição do evento traumático e de todos os eventos subsequentes com ele relacionados, a partir da informação colhida através da vítima ou de quem a acompanhe, bem como a partir dos registos clínicos relativos ao acidente em causa. Devem, pois, incluir sistematicamente no relatório pericial os seguintes aspetos: 
(a) Data, local, mecanismo, tipo e circunstâncias do evento traumático; (b) Lesões resultantes (descrição genérica, de acordo com a informação prestada pela vítima e descrição detalhada de acordo com a informação dos registos clínicos); (c) Estabelecimentos médicos onde foi assistida, complicações surgidas e tratamentos efetuados; (d) Internamento(s) e data(s) de alta(s) hospitalar(es); (e) Consulta(s) em ambulatório e respetiva(s) data(s) de alta(s); (f) Data(s) de retoma(s) da atividade profissional ou outras circunstâncias, como a mudança de atividade, desemprego ou aposentação.

Consta, ainda, das referidas Recomendações, que a descrição dos danos deve ser rigorosa, clara, objetiva, pormenorizada, sistematizada e compreensível, nomeadamente para não médicos. Assim, para se garantir uma descrição global e personalizada do dano, pode seguir-se o modelo da avaliação tridimensional que inclui três níveis (MAGALHÃES T, 1998): corpo, funções e situações.

As sequelas no "corpo", ou seja, os aspetos biológicos com as suas particularidades morfológicas, anatómicas, histológicas, fisiológicas e genéticas (HAMONET \& MAGALHÃES, 2000), devem ser descritas de forma orientada e rigorosa, com indicação de todas as características das lesões ou sequelas, incluindo: (a) Tipo (equimose, escoriação, ferida cortante, etc., no caso das lesões; cicatriz, dismorfia, amiotrofia, dismetria, alteração da amplitude ou da estabilidade articular, desvio do eixo ou rotação do membro, perda de segmento ou órgão, alteração na força, sensibilidade, equilíbrio, etc., no caso das sequelas); (b) Localização precisa; (c) Cor (quando for caso disso); (d) Dimensões exatas (medindo dimensões e graus e, no caso do exame ortopédico e neurológico, comparando com o lado contra lateral sempre que possível). Deve ser também feita referência independente a eventuais alterações encontradas que sejam resultantes de um estado anterior (MAGALHÃES e col, 2010). O exame pode descrever-se de acordo com as seguintes regiões anatómicas (MAGALHÃES e col, 2010): crânio; face; pescoço; coluna (medula incluída); tórax; abdómen (conteúdo pélvico e períneo incluídos); membro superior direito; membro superior esquerdo; membro inferior direito (pelve óssea incluída); membro inferior esquerdo (pelve óssea incluída). Sempre que possível as lesões e sequelas corporais devem ser fotografadas, de acordo com as normas da fotografia forense, e com o prévio consentimento da vítima ou seu representante legal, fazendo-se referência às fotografias no relatório pericial.

As sequelas "funcionais" correspondem às capacidades físicas e mentais (atuais ou potenciais) próprias do ser humano, tendo em conta a sua idade e sexo, independentemente do meio onde este se encontre; surgem na sequência das sequelas a nível do corpo e são influenciadas, positiva ou negativamente, por fatores pessoais (como a idade, o estado físico e psíquico anterior, a motivação e o esforço pessoal de adaptação) e do meio (como as barreiras 
arquitetónicas, ajudas técnicas ou ajudas humanas). Podem descrever-se relativamente aos seguintes aspetos: (a) postura, deslocamentos e transferências; (b) manipulação e preensão; (c) comunicação; (d) cognição e afetividade; (e) controlo de esfíncteres; (f) sexualidade e procriação. (HAMONET \& MAGALHÃES, 2000)

As sequelas "situacionais" correspondem à confrontação (concreta ou não) entre uma pessoa e a realidade de um meio físico, social e cultural; podem ser relativas às atividades da vida diária, familiar, social, de lazer, de educação, de trabalho ou a outras, num quadro de participação social. Surgem em consequência das sequelas a nível do corpo e das funções, variando com os fatores pessoais e do meio. As situações de vida devem ser descritas quanto aos prejuízos mais relevantes, de acordo com os seguintes aspetos: (a) atos da vida corrente; (b) vida afetiva, social e familiar; (c) vida profissional ou de formação. (HAMONET \& MAGALHÃES, 2000)

As normas para avaliação de cada um dos níveis referidos podem ser consultadas nas "Instruções para utilização do Inventário de Avaliação do Dano Corporal" (MAGALHÃES T, 1998).

\section{Nexo de causalidade}

A problemática do nexo de causalidade constitui assunto de particular relevância, sendo um momento decisivo para toda a perícia (VIEIRA \& CORTE-REAL, 2008). A causalidade médica é a noção que permite admitir cientificamente a relação existente entre um facto ou evento e um estado patológico, por exemplo, entre um acidente e uma fratura ou entre uma fratura e uma anquilose (FOURNIER \& HUGUES-BÉJUI, 2003). Assim, antes de avançar para a valoração da alteração da saúde ou integridade psicofísica consequente a um traumatismo, o nexo de causalidade precisa de ser analisado, podendo a lesão ser, ou não, imputada ao acidente (LUCAS, 2005).

No presente estudo verificou-se que, apesar do constante da Lei 6194/1974, de 19 de dezembro (DPVAT), relativamente à exigência de verificação do nexo de causalidade entre o evento e o dano para atribuição da indemnização por aquele seguro, em 100\% dos casos esta avaliação não está descrita nos relatórios médico-legais.

Para além do mais, falham aspetos nos relatórios, já atrás identificados, fundamentais para que o perito possa equacionar a existência deste nexo e fundamentá-lo, se o mesmo se comprovar: é o caso dos antecedentes pessoais patológicos e/ou traumáticos que possam ser relevantes ou influenciar o resultado final do estado sequelar relativo ao caso em análise (recolhidos com base 
na informação da vítima ou seu acompanhante e/ou em registos clínicos); tal será fundamental para a ponderação daquele nexo, nomeadamente por poder dar indicações quanto ao eventual estado anterior da pessoa relativamente ao traumatismo; mas é também o caso do mecanismo do traumatismo e das lesões e sequelas resultantes.

Ora, é fundamental que se explique o raciocínio que sustenta a passagem da causa ao efeito, explicação que deve ter coerência científica (VIEIRA \& CORTE-REAL, 2008). Por isso, devem ser sistematicamente discutidas nos relatórios médico-legais as sete condições clássicas para se estabelecer o nexo de causalidade entre o traumatismo e o dano, citadas em todos os textos sobre a matéria, designadamente por Oliveira Sá (1992): (a) Natureza adequada do traumatismo para produzir as lesões evidenciadas; (b) Natureza adequada das lesões a uma etiologia traumática; (c) Adequação entre a sede do traumatismo e a sede da lesão; (d) Encadeamento anatomoclínico; (e) Adequação temporal; (f) Exclusão da preexistência do dano relativamente ao traumatismo; (g) Exclusão de uma causa estranha ao traumatismo.

A "Natureza adequada do traumatismo para produzir as lesões evidenciadas" significa que deve existir uma proporção entre a intensidade do traumatismo e a quantidade de dano produzido. O critério de "Natureza adequada das lesões a uma etiologia traumática" significa que é preciso que a condição médica em análise seja daquelas para as quais a ciência aceite uma possível origem traumática. A "Adequação entre a sede do traumatismo e a sede da lesão" estabelece a necessidade de uma relação entre o local do traumatismo e a sede do dano (CRIADO DEL RÍO, 1999). O critério de "Encadeamento anatomoclínico" trata de demonstrar a concatenação lógica e coerente dos fenómenos colocados em marcha pelo traumatismo (CALABUIG, 2001). A "Adequação temporal" refere que o intervalo livre entre o traumatismo e o dano deve ser compatível e adequado a uma etiologia traumática (OLIVEIRA SÁ, 1992). O critério de "Exclusão da preexistência do dano relativamente ao traumatismo" é necessário para excluir um facto coincidente, ou seja, um dano corporal que já existia e que, sendo revelado após o trauma, não guarda relação com este. Por fim, a "Exclusão de uma causa estranha ao traumatismo" é o critério que procura verificar se existe outra causa ou circunstância exclusiva e plenamente capaz de explicar o dano (CRIADO DEL RÍO, 1999).

Estes critérios devem constituir elementos de reflexão, a serem interpretados cuidadosa e ponderadamente em cada situação concreta, de modo a permitir ao perito chegar a uma convicção científica. Havendo, eventualmente, dúvidas quanto à imputabilidade médica, deve o perito explicitá-la através da análise do nexo de causalidade hipotético, indireto ou parcial. (VIEIRA \& CORTE-REAL, 2008) 


\section{Data de consolidação médico-legal das lesões}

A evolução das lesões, resultantes de um traumatismo, corresponde sempre a um estado temporário que evolui até ao estabelecimento das sequelas ou à sua cura (MAGALHÃES, 1998). Assim, verificada a existência de nexo de causalidade entre o evento traumático em causa e o dano resultante, a primeira missão do perito é estabelecer a data de cura ou de consolidação médico-legal das lesões.

Do ponto de vista médico-legal, fala-se em cura sempre que o indivíduo recuperou totalmente das lesões sofridas, voltando a estar exatamente na mesma situação em que se encontrava antes do dano ter sido produzido (VIEIRA, 2000).

Fala-se em consolidação médico-legal quando persistem sequelas, ou seja, um dano corporal de caráter permanente. A vítima pode ter alta médica definitiva ou manter tratamentos, mas apenas para evitar um agravamento, não sendo razoável admitir alterações significativas no quadro clínico apresentado (VIEIRA, 2000).

No caso da cura serão avaliadas apenas as repercussões temporárias do dano, enquanto no caso da consolidação se consideram as consequências temporárias e permanentes. Assim, é fundamental a determinação dessa data, sem a qual não se sabe quando terminam os danos temporários e começam os permanentes. A determinação desta data pode ter em conta vários aspetos, existindo até situações particulares que devem ser consideradas mas em geral corresponde à data de alta da última consulta médica (MAGALHÃES T e col, 2010). No caso de não existir informação, designadamente nos registos clínicos hospitalares, e outros, para esta avalição, pode recorrer-se à literatura para estimar o tempo que determinado tipo de lesões demandam para a cura (PÉREZ MG-B, 2006; RAMIREZ LB, 1996).

$\mathrm{O}$ que se verificou no presente estudo, é que os relatórios médico-legais analisados eram omissos a este aspeto em $100 \%$ dos casos.

\section{Parâmetros de dano temporário}

Os danos temporários, económicos e não económicos, são suscetíveis de serem indemnizados, pelo que devem ser rigorosa e sistematizadamente descritos nos relatórios periciais. A metodologia de avaliação destes danos, no âmbito do Direito Civil, consta das "Recomendações gerais para a realização de relatórios periciais de clínica forense no âmbito do Direito Civil" do Instituto Nacional de Medicina Legal, I.P., de Portugal (MAGALHÃES \& VIEIRA, 2010), importando fazer referência a alguns aspetos, ainda que resumidamente. 
Quer a vítima exerça ou não uma atividade profissional, existe um momento em que as lesões determinam um comprometimento das suas atividades habituais. Esse período, chamado de défice funcional temporário, será total nos períodos de hospitalização ou restrição ao leito no domicílio, presumindo-se um relevante prejuízo na autonomia da vítima. Com o tempo, as lesões que inicialmente determinam um défice total evoluem para um défice funcional parcial. Em síntese, o défice temporário funcional pode ser total ou parcial, de acordo com o grau de comprometimento da autonomia da vítima. Tem a sua duração limitada pela data do traumatismo e pela data estimada de cura ou consolidação médico-legal das lesões, conforme restituição anatómica e funcional integral ou evolução para sequelas, respetivamente (MAGALHÃES \& VIEIRA, 2010).

Durante esse período de recuperação da vítima é comum que ocorram impedimentos ou restrições para o seu retorno ao trabalho. Essa repercussão temporária nas atividades profissionais será total se a vítima não tiver condições de realizar nenhuma das tarefas fundamentais de sua profissão; será parcial durante o período em que esta estiver incapacitada de retornar ao seu trabalho de forma integral, mas puder retomá-lo parcialmente (VIEIRA, 2008).

Nesse período de danos temporários valora-se, ainda, o quantum doloris, que corresponde à dor física resultante dos ferimentos e dos tratamentos, e a dor em sentido psicológico, incluindo a angústia e ansiedade quanto ao acidente e hospitalização, a consciência do risco de vida, o afastamento do meio, bem como das responsabilidades familiares e profissionais (OLIVEIRA SÁ, 1992).

No caso do presente estudo, estes danos eram omissos em 100\% dos casos.

\section{Parâmetros de dano permanente}

Também os danos permanentes, económicos e não económicos, são suscetíveis de serem indemnizados, pelo que devem ser rigorosa e sistematizadamente descritos nos relatórios periciais. Neste estudo, a referência a qualquer um destes danos era omissa em 93.3\% dos casos.

A metodologia de avaliação destes danos, no âmbito do Direito Civil, consta das "Recomendações gerais para a realização de relatórios periciais de clínica forense no âmbito do Direito Civil” do Instituto Nacional de Medicina Legal, I.P., de Portugal (MAGALHÃES \& VIEIRA, 2010), fazendo-se aqui uma sumária referência a algumas questões.

Uma dessas perspetivas é a apreciação da alteração ou o défice permanente da integridade física elou psíquica da pessoa com repercussão nas suas atividades da vida diária. É descrito pelo perito e avaliado em pontos ou 
percentagens, tendo como referência tabelas funcionais de dano corporal em Direito Civil (VIEIRA, 2008).

No caso português, as normas referem que este constitui um dano que, sendo personalizado, deve ser valorado de igual forma em todos os casos, independentemente da atividade profissional, tendo em conta a globalidade das sequelas do caso concreto (corpo, funções e situações) e tendo como elemento indicativo de referência a Tabela de Avaliação de Incapacidades em Direito Civil (Anexo II do Decreto Lei 352/2007, de 23 de outubro). A tabela brasileira não é completamente sobreponível a esta, sendo mais reduzida, mas constitui um instrumento válido que, como todos, poderá ser sempre melhorado, o qual deveria ser usada sistematicamente para a quantificação deste dano (no caso, dito de invalidez).

Deve ser também avaliada a repercussão das sequelas nas atividades profissionais da vítima. Esta repercussão corresponde às consequência da alteração permanente da integridade física e/ou psíquica a nível do exercício profissional. Podem ser verificadas as seguintes situações (OLIVEIRA SÁ, 1992; MAGALHÃES \& VIEIRA, 2010): (a) Compatibilidade com o exercício de sua atividade profissional; (b) Compatibilidade com o exercício de sua atividade profissional, mas implicando esforços suplementares no exercício da mesma; (c) Impedimento do exercício de sua atividade profissional, havendo, no entanto, compatibilidade com outras profissões na área da sua preparação técnico-profissional; (d) Impedimento do exercício de sua atividade profissional, bem como de qualquer outra na área de sua preparação técnico-profissional.

Outra perspetiva a ser tida em conta na avaliação das sequelas é a questão do dano estético permanente imputável ao traumatismo que, no nosso estudo, apesar de só ter sido considerado em 9 casos foi, ainda assim, o mais frequentemente considerado. Correspondente à repercussão de uma sequela estática (e.g., cicatriz, deformidade) ou dinâmica (e.g., claudicação da marcha, alterações na mímica), resultando na deterioração da imagem da vítima em relação a si própria e aos outros. Devem ser levados em conta o grau de notoriedade/visibilidade e o desgosto revelado pela vítima (MAGALHÃES \& VIEIRA, 2010).

A repercussão na atividade sexual da vítima corresponde à impossibilidade total ou parcial que encontra o indivíduo - em consequência das sequelas físicas e/ou psíquicas - para manter o mesmo tipo de atividade sexual que tinha anteriormente à vivência do evento traumático, não se incluindo os aspetos relacionados à capacidade reprodutora (MAGALHÃES \& VIEIRA, 2010).

Outro aspeto a se ter em conta na avaliação das sequelas é a repercussão nas atividades desportivas e de lazer da vítima. Avalia-se o prejuízo funcional para a vítima se dedicar a certas atividades culturais, desportivas ou de 
lazer que exercia com regularidade e representavam para esta uma ampla gratificação pessoal (MAGALHÃES \& VIEIRA, 2010).

Por fim, o perito deve fazer referência às dependências da vítima e suas necessidades futuras, o que se aplica, sobretudo, no caso dos traumatizados graves. No caso em estudo se verificou, ainda assim, em 40 casos (15.7\%), o que até se encontra acima da taxa de casos esperada nestas situações (MAGALHÃES, 1998). As dependências podem ser temporárias ou permanentes, sendo valorizadas enquanto tal, mais frequentemente, as permanentes. Podem ser relativas a diversos tipos de necessidades: medicamentosas, tratamentos clínicos, ajudas técnicas, adaptações (domicílio, local de trabalho, viatura), ou ajuda de terceira pessoa (MAGALHÃES \& VIEIRA, 2008).

\section{0 relatório pericial}

A metodologia de elaboração do relatório pericial no Brasil, e para estes casos, seguida nos IML em geral é a do Direito Penal, o que não promove a avaliação dos diversos parâmetros de dano acima elencados, suscetíveis de serem traduzidos numa indemnização fundamentada, sendo, antes, danos que melhor se aplicam à qualificação jurídico-penal de uma conduta.

De acordo com as normas portuguesas (MAGALHÃES e col, 2010), o modelo deve ser praticamente igual para todos os âmbitos do Direito em que o exame tenha lugar (Penal, Civil, Trabalho, Família ou Administrativo), até ao capítulo da Discussão, importando depois ter em conta as especificidades e objetivos de cada Direito nos capítulos da Discussão e Conclusões.

Assim, é fundamental conhecer as regras e objetivos do Direito que regem cada tipo de perícia e estar consciente das implicações que o relatório pericial terá na decisão judicial. O relatório possui, em termos probatórios, valor particularmente relevante. É um testemunho escrito de natureza médica, relativo a uma situação da qual analisa as causas e consequências. A sua leitura deverá permitir reconstituir, sem equívocos, todas as observações feitas pelo perito e todos os elementos que fundamentam as conclusões da perícia que concretizou, de forma a que esta possa ser também eventualmente submetida a um saudável contraditório em sede de julgamento ou vir a ser posteriormente possível em caso de eventual agravamento (MAGALHÃES e col, 2010).

O objetivo do relatório pericial é, pois, promover a correta descrição e análise do evento traumático e da sua vivência, dos elementos de dano temporários (lesões, períodos de incapacidade e eventuais tratamentos e complicações) e permanentes (sequelas corporais, funcionais e situacionais), e a ponderação/avaliação do nexo de causalidade entre o traumatismo e as lesões 
ou sequelas, bem como da data de cura/consolidação das lesões, visando a posterior avaliação dos diversos parâmetros de dano na pessoa (classicamente designado por dano corporal) em função do enquadramento legal da perícia (VIEIRA, 2000; VIEIRA, 2008; MAGALHÃES \& VIEIRA, 2010).

Portanto, o relatório em Direito Civil, deverá conter, além dos elementos descritivos próprios da avaliação pericial do dano corporal, um capítulo com a discussão dos pontos relevantes, que resumidamente se elencam: nexo de causalidade; data de cura ou consolidação das lesões; danos temporários (períodos de défice funcional temporário total e parcial; períodos de repercussão temporária nas atividades profissionais total e parcial e quantum doloris); danos permanentes (défice funcional da integridade psicofísica expresso em pontos ou percentagem, repercussão das sequelas nas atividades profissionais, dano estético permanente quantificado numa escala de sete graus de gravidade crescente, repercussão das sequelas na vida sexual, quantificada no mesmo tipo de escala, repercussão das sequelas nas atividades desportivas e de lazer, usando também a mesma escala, e referência a dependências ou necessidades futuras da vítima).

Deverá ser considerado um capítulo inicial, de "Informação", o qual deve compreender dois subcapítulos - "História do Evento" e "Dados Documentais" -, onde o perito descreverá o evento traumático e todos os eventos subsequentes com ele relacionados, com base na informação da vítima ou de quem a acompanhe, incluindo data, local, mecanismo, tipo e circunstâncias do evento traumático, lesões resultantes, estabelecimentos médicos onde foi assistida, complicações surgidas, tratamentos efetuados, internamentos e datas de alta, consultas em ambulatório e alta, retomada da atividade profissional ou outras circunstâncias, como a mudança de atividade, desemprego ou aposentação (MAGALHÃES \& VIEIRA, 2010). Deve constar, ainda, no capítulo da "Informação", os dados documentais, geralmente registos clínicos, elementos fundamentais para o melhor conhecimento, descrição e comprovação das lesões sofridas, de eventuais complicações e dos tratamentos efetuados (MAGALHÃES \& VIEIRA, 2010).

Posteriormente deve ser elaborado um capítulo relativo aos "Antecedentes pessoais". Deve-se interrogar a vítima, ou quem a represente, sobre os seus antecedentes médicos e obter informação clínica sobre eles, apenas assinalando e discutindo no relatório os que constituem um estado anterior suscetível de ter incidência sobre as lesões, a sua evolução e as sequelas observadas (HUGUES-BEJUI, 2006). Este capítulo é fundamental no âmbito da ponderação do nexo de causalidade entre o traumatismo e o dano, nomeadamente pela circunstância de poder dar indicações quanto a eventual estado anterior da pessoa relativamente ao traumatismo (MAGALHÃES \& VIEIRA, 2010). 
O capítulo seguinte deverá referir-se ao "Estado atual” da vítima, onde se incluem as "Queixas", o "Exame objetivo" e os "Exames complementares". Como o objeto da perícia é a pessoa, englobando os danos por ela sofridos, estes serão considerados em três níveis (corpo, funções e situações de vida), cuja correlação permitirá compreender a relação de causalidade entre os danos no corpo e os danos para a vida concreta do indivíduo em causa (MAGALHÃES \& VIEIRA, 2010). As queixas devem contemplar os danos relativamente às "funções" e "situações de vida"; no caso dos handicaps graves a descrição pormenorizada e multidisciplinar destas queixas é fundamental (MAGALHÃES \& VIEIRA, 2008). No “Exame objetivo” descreve-se o dano no "corpo", referindo-se o estado geral da pessoa e depois uma descrição orientada e rigorosa, com indicação de todas as características das lesões ou sequelas (MAGALHÃES \& VIEIRA, 2010); deve-se proceder a um exame clínico detalhado em função das lesões iniciais e das queixas expressas pela vítima, consignando-se todas as constatações no relatório pericial (HUGUES-BEJUI, 2006). Como complemento desta observação pode justificar-se documentar fotograficamente as lesões ou sequelas, incorporada no relatório após prévia autorização escrita da pessoa (MAGALHÃES \& VIEIRA, 2010).

Eventualmente, podem ser necessários exames complementares, como exames imaginológicos, pareceres de especialidades e outros, os quais também devem ser descritos no relatório pericial (MAGALHÃES \& VIEIRA, 2010).

Posteriormente à identificação e descrição dos danos, procede-se à sua interpretação e valoração no capítulo da "Discussão", tendo como ponto de partida o estudo do nexo de causalidade e o estabelecimento da data de consolidação médico-legal das lesões, conforme acima descrito. Nessa sequência, descrevem-se, quantificam-se e fundamentam-se os parâmetros de dano temporário e os parâmetros de dano permanente.

Finalmente, as "Conclusões" deverão constituir um resumo do que consta no capítulo da "Discussão".

O relatório deve integrar as respostas aos quesitos, devendo evitar-se, sempre que possível, responder-lhes diretamente, dado que estes constituem um autêntico espartilho para os peritos, tentando, por vezes, condicionar a sua resposta (OLIVEIRA SÁ, 1992), e não permitindo a integração dessas respostas no contexto de todo o quadro clínico.

\section{Reflexão final}

O presente estudo não nos aporta quaisquer resultados que não fossem expectáveis, mas constitui a comprovação, analisada à luz de critérios científicos, daquilo que já é um dado adquirido: a falta de normas e a falta 
de cumprimento das que existem, no que toca à avaliação médico-legal do dano corporal por acidente de viação no Brasil, tendo em vista contribuir para a determinação da indemnização a atribuir às vítimas, bem como as graves consequências desses factos, traduzidas pela "pobreza" dos relatórios periciais elaborados para esse fim.

Ficam agora a faltar outros estudos, fundamentais para completar o presente e melhor caracterizar esta situação no Brasil, designadamente, estudos sobre a perspetiva dos médicos peritos, dos magistrados e dos seguradores quanto ao sistema atual e quanto a uma eventual abertura a um novo modelo e, ainda, um estudo sobre as indemnizações atribuídas, que permitisse analisar o peso da perícia médico-legal na decisão judicial ou da seguradora.

Parece-nos que os modelos seguidos em Portugal, com as devidas adaptações à realidade brasileira, sobretudo aos aspetos legais, poderiam constituir um importante contributo à promoção da qualidade das perícias efetuadas no Brasil, orientando-as melhor para o objetivo que se propõem servir.

De facto, e como atrás se deixou já exposto, um relatório pericial deve descrever de forma clara, objetiva e pormenorizada o dano corporal, identificando os conceitos e instrumentos usados na avaliação (e.g., significado dos parâmetros de dano, escalas e tabelas a que se recorra) e baseando-se, sempre que possível, na consulta de documentos clínicos (a prova do dano implica o conhecimento do estado anterior e posteriormente ao evento). Deve ter em consideração a informação dada pela vítima ou seu acompanhante e indicar a origem das informações usando tempos verbais adequados ao grau de fiabilidade dessa informação. Deve, ainda, conter a descrição, análise e interpretação do dano corporal sofrido pela pessoa, de modo a permitir a sua compreensão por todas as partes envolvidas. (MAGALHÃES \& VIEIRA, 2010)

Por isso, todos os momentos do exame são importantes, a começar pela correta identificação da vítima, passando pela descrição de certos aspetos com ela relacionados, que serão fundamentais para melhor compreender a repercussão dos danos sofridos, como informações sobre o seu modo de vida, saúde prévia ou as suas condições de atividade profissional; se se tratar de uma criança, de um estudante ou de um aluno em formação profissional, importará precisar o seu nível escolar, a natureza dos seus diplomas ou da formação; e, no caso de alguém à procura de emprego, deve precisar-se a sua formação (HUGUES-BEJUI, 2006).

E naturalmente, pelos motivos atrás expostos, todos os aspetos que caraterizam o dano e a sua vivência são também absolutamente fundamentais, como a descrição pormenorizada do acidente, das lesões sofridas, dos tratamentos que tiveram lugar, dos internamentos, consultas e suas datas de início e término, da forma como a vítima vivenciou todo este processo, 
etc. (MAGALHÃES \& HAMONET, 2000; MAGALHÃES 2005; MAGALHÃES e col. 2010).

Posteriormente, o relatório pericial deverá compreender sempre dois momentos fundamentais (MAGALHÃES \& VIEIRA, 2010): (a) Identificação e descrição dos danos, temporários e permanentes, com base na entrevista, nos elementos documentais e nos exames efetuados; (b) Interpretação e valoração dos elementos observados e elaboração de conclusões devidamente fundamentadas.

Um exame pericial e seu respetivo relatório elaborados nestes termos, poderão contribuir, desde logo, para uma melhor satisfação e realização profissional do perito médico, para um melhor serviço à Justiça, e para uma melhor e mais justa satisfação da vítima, visando não só promover a sua saúde, reabilitação, reintegração familiar, social e profissional, bem como a sua dignidade e qualidade de vida e, ainda, minorar os danos colaterais que nestes casos afetam sempre as famílias e a comunidade em geral.

Assim, importa analisar melhor esta matéria e sobre ela refletir com ponderação, dada a relevância das questões em causa (a Justiça e a adequada reintegração das vítimas de acidentes), sendo que o modelo português de avaliação do dano corporal pós-traumático em Direito Civil, com as devidas adaptações, se pode perfeitamente adequar à realidade brasileira, o que traria, seguramente, vantagens acrescidas à realização deste tipo de atividade, vantagens essas extensivas ao serviço da Justiça, às vítimas e a todos quantos neste processo se vêm envolvidos.

\section{CONCLUSÕES}

A partir deste estudo pode concluir-se que os relatórios médico-legais elaborado no IML de Belo Horizonte por motivo de acidente de viação, e tendo como objetivo a reparação do dano corporal, são altamente omissos relativamente a aspetos fundamentais que importa que constem, sistematicamente de um relatório deste tipo. Assim, verificou-se que destes relatórios não consta:

a) Dados sobre a vítima como idade e estado civil (3.1\% e 8.3\%, respetivamente);

b) Antecedentes patológicos e traumáticos da vítima (100\%);

c) Data do acidente $(86.6 \%)$;

d) Caraterização do acidente (81.9\%);

e) Referência ao tipo de veículo envolvido (68.5\%) 
f) Local e tipo de lesões sofridas (20.5\% e $31.9 \%$, respetivamente);

g) Sequelas corporais, funcionais e situacionais $(3.1 \%, 9.1 \%$ e $79.5 \%$, respetivamente);

h) Nexo causalidade entre o traumatismo e o dano (100\%);

i) Data de consolidação médico-legal das lesões (100\%);

j) Parâmetros de dano temporário (100\%);

k) Parâmetros de dano permanente (93.3\%).

Não significam estes resultados que os relatório analisados constituam um documento vazio, e sem informação mas, antes, que num elevadíssimo número de casos os peritos médico-legais se limitam a dar apenas resposta direta aos quesitos que lhes são colocados. Este facto, que reduz de forma clara o valor e importância do relatório pericial para a adequada determinação da indemnização a atribuir, exige um profunda reflexão no sentido de se encontrar um caminho para mudar os procedimentos nesta matéria, sendo que, de acordo com o que atrás se expôs, consideramos que o modelo do Instituto Nacional de Medicina Legal, I.P., de Portugal, largamente validado no âmbito do Direito Civil, pode ser adaptado à realidade brasileira com evidentes vantagens a nível da qualidade pericial e da possibilidade de harmonização das práticas, aspeto fundamental para uma boa administração da Justiça.

\section{REFERÊNCIAS BIBLIOGRÁFICAS}

ANGHER JA. Vade Mecum acadêmico de direito. Décima Edição. São Paulo: RIDEEL, 2010.

BOROBIA C. Valoración del daño corporal: legislación, metodología y prueba pericial médica; Barcelona: Masson; 2006.

CALABUIG JA. Medicina Legal y Toxicología; $5^{\text {a }}$ ed, Barcelona: Masson; 2001.

CRIADO DEL RÍO MT. Valoración médico-legal del daño a la persona; Madrid: Colex; 2010.

CUETO CH. Valoración médica del daño corporal; $2^{\mathrm{a}}$ ed, Barcelona: Masson; 2001.

DENATRAN. [Documento online] Disponível em www.denatran.gov.br [acedido em 11 maio 2010].

DPVAT. Leis e resoluções. [Documento on line] Disponível em dpvatseguro.com.br/conheca/ leis_e_resolucoes.asp [acedido em 11 maio 2010] e dpvatseguro.com.br/documentos/ Lei\%206194_alterações_Lei\%2011945.pdf [acedido em 26 junho 2010].

ESTATÍSTICAS DE TRÂNSITO, 2010. [Documento online] Disponível em: wportaldotransito. com.br/estatisticas-de-transito [acedido em 4 janeiro 2011]

ESTEVAN A. Los accidentes de automóvil: una matanza calculada. [Documento online] 2001. Disponível em iieh.com/images/stories/Sociedad/PDF/los\%20accidentes $\% 20$ de $\% 20$ automovil.pdf [acedido em 19 junho 2011]. 
FOURNIER C, HUGUES-BEJUI H. L'imputabilité médicale en droit commun. Un siècle de réflexin sur la relation de cause à effet en dommage corporel. Revue Française Dommage Corporel 2003; 29(3): 277-88.

FRAGOSO HC. Lições de Direito Penal: parte especial. $3^{a}$ ed. São Paulo: Bushatsky, 1976.

FRANÇA GV. Medicina Legal. $7^{\mathrm{a}}$ ed. Rio de Janeiro: Guanabara Koogan, 2004.

HAMONET C, MAGALHÃES T. Système d'Identification et Mésure des Handicaps, Paris : ESKA, 2000.

HUGUES-BEJUI H. La mission d'expertise en droit commun. Revue Française Dommage Corporel 2006; 2:113-8.

JORGE MHPM, KOIZUMI MS. Acidentes de trânsito no Brasil: um atlas de sua distribuição. São Paulo: Abramet, 2007.

KHAN ZU, ASIRI KMAL, IQBAL J. Injury patterns from road traffic accidents. Pak J Med Sci 2010; 26(2): 394-397.

LUCAS FM. Avaliação das sequelas em direito civi. Coimbra: Gráfica de Coimbra, 2005.

MAGALHÃES T, CORTE-REAL F, SANTOS JC, VIEIRA DN. Recomendações gerais para a realização de relatórios periciais de clínica forense relativos ao dano pós-traumático. Revista Portuguesa do Dano Corporal 2010; 20: 53-61.

MAGALHÃES T, VIEIRA DN. A avaliação dos grandes traumatizados e a avaliação de terceira pessoa. In: Vieira DN e Quintero JA eds. Aspectos práticos da avaliação do dano corporal em Direito Civil. Coimbra: Caixa Seguros e Imprensa da Universidade de Coimbra. 2008. pp 59-69.

MAGALHÃES T, VIEIRA DN. Recomendações gerais para a realização de relatórios periciais de clínica forense no âmbito do direito civil. Revista Portuguesa do Dano Corporal, 20:70-90, 2010.

MAGALHÃES T. Estudo tridimensional do dano corporal: lesão, função e situação. Sua aplicação médico-legal. Coimbra: Almedina, 1998.

MAGALHÃES T: A vítima como objecto da intervenção médico-legal. Acta Med Port 2005; 18: 453-8.

MAGALHÃES T, HAMONET C. O dano pessoal. Revista Portuguesa do Dano Corporal 2000; 9(10):49-69.

MARIN L, QUEIROZ MS. A atualidade dos acidentes de trânsito. Cad. Saúde Pública 2000; 16:7-21.

MARTINS RT. Seguro DPVAT. Seguro Obrigatório de Veículos Automotores de Vias Terrestres. Campinas/SP: Servanda, 2009.

OLIVEIRA NLB. Retorno à atividade produtiva de motociclistas vítimas de acidentes de trânsito. Acta Paul Enferm 2006; 19(3):284-9.

OLIVEIRA SÁ F. Clínica Médico-Legal da reparação do dano corporal em direito civil; Coimbra: APADAC, 1992.

PÉREZ MG-B. Nuevo Manual de Valoración y Baremación del Daño Corporal. $14^{\circ}$ ed. Granada: Editorial Comares, 2006.

RAMÍREZ LB. Tiempos de Curación en Traumatologia. Madrid: Praxis 2.000, 1996.

REDE SARAH DE HOSPITAIS DE REABILITAÇÃO. [Documento online]. Disponívl em sarah.br/ [acedido em 4 janeiro 2011]. 
RIZZARDO A. A reparação nos acidentes de trânsito. $8^{a}$ ed. São Paulo: Revista dos Tribunais, 1998.

SANTOS RB. Direito de Seguro no novo Código Civil e legislação própria. Rio de Janeiro: Forense, 2006.

VIEIRA DN, CORTE-REAL F. Nexo de causalidade em Avaliação do Dano Corporal. In: Vieira DN e Quintero JA eds. Aspectos práticos da avaliação do dano corporal em Direito Civil. Coimbra: Caixa Seguros e Imprensa da Universidade de Coimbra, 2008, pp.61-83.

VIEIRA DN. A “missão” de avaliação do dano corporal em direito civil. Sub Júdice 2000; 17:23-30.

VIEIRA DN. O Perito e a missão pericial em Direito Civil. In: Vieira DN e Quintero JA eds. Aspectos práticos da avaliação do dano corporal em Direito Civil. Coimbra: Caixa Seguros e Imprensa da Universidade de Coimbra, 2008, pp 35-59.

Resumo: Avaliação do dano corporal no Brasil. 0 caso dos acidentes de viação Não existe no Brasil uma norma específica para avaliação do dano corporal pós-traumático em sede de Direito Civil, seguindo-se antes, na maioria dos Institutos de Medicina Legal, o modelo do Direito Penal; mesmo a tabela de invalidez oficialmente prevista e outras orientações legais existentes não são geralmente usadas. Este facto em nada pode beneficiar a qualidade das perícias e é, seguramente, prejudicial para a boa administração de justiça. Assim, o presente estudo tem como objetivo geral analisar do ponto de vista médico-legal e forense a metodologia de avaliação do dano corporal em vítimas de acidentes de viação no Brasil para, a partir dos resultados obtidos, refletir sobre os procedimentos adotados em termos desta metodologia, tendo como elementos de comparação o modelo em uso no Instituto Nacional de Medicina Legal, I.P., de Portugal. Foi efetuado um estudo observacional, com componente analítico, que consistiu numa análise de relatórios médicos médico-legais elaborados no IML de Belo Horizonte, relativos a acidentes de viação $(n=254)$. Os relatórios são altamente omissos relativamente a: (a) dados sobre a vítima como idade e estado civil (3.1\% e $8.3 \%$, respetivamente); (b) antecedentes patológicos e traumáticos da vítima (100\%); (c) data do acidente $(86.6 \%)$; (d) caraterização do acidente $(81.9 \%)$; (e) referência ao tipo de veículo envolvido (68.5\%); (f) local e tipo de lesões sofridas $(20.5 \%$ e $31.9 \%$, respetivamente); (g) sequelas corporais, funcionais e situacionais $(3.1 \%, 9.1 \%$ e $79.5 \%$, respetivamente); (h) nexo de causalidade entre o traumatismo e o dano (100\%); (i) data de consolidação médico-legal das lesões (100\%); (j) parâmetros de dano temporário (100\%); (k) parâmetros de dano permanente (93.3\%). Significam isto que num elevadíssimo número de casos os peritos se limitam a dar apenas resposta direta aos quesitos. Este facto exige uma profunda reflexão no sentido de se encontrar um caminho para mudar os procedimentos nesta matéria, dada a relevância das questões em causa.

Palavras-chave: Dano corporal; Acidente de viação; Avaliação médico-legal; Perícia médica; Direito Civil; Indemnização. 
Summary: Assessment of bodily harm in Brazil. The case of road traffic accidents In Brazil there is no specific norm for the assessment of bodily harm within the Civil Law. The Criminal Law model is followed in most of the Legal Medicine Institute; even the disability table predicted and other legal directions are not often used. This cannot in any way benefit the quality of evaluations and is certainly harmful to the good administration of Justice. Therefore, the general objective of the present study is to analyze, from the forensic viewpoint, the methodology for the assessment of bodily harm in victims of road traffic accidents in Brazil in order to, from the results obtained, think over the procedures adopted in terms of such methodology, having as element of comparison the model in use at the National Institute of Legal Medicine from Portugal. An observational study with an analytical component was carried out, consisting of the analysis of forensic reports elaborated at the IML of Belo Horizonte, referring to road traffic accidents ( $n=254)$. The reports fail to include: (a) data about the victim such as age and marital status $(3.1 \%$ and $8.3 \%$, respectively); (b) the victim's pathological and traumatic history $(100 \%)$; (c) date of the accident $(86.6 \%)$; (d) characterization of the accident $(81.9 \%)$; (e) reference to the kind of vehicle involved $(68.5 \%)$; (f) place and kind of injuries suffered $(20.5 \%$ and $31.9 \%$, respectively); (g) physical, functional and situational sequels $(3.1 \%, 9.1 \%$ and $79.5 \%$, respectively); (h) causality between the trauma and the bodily harm (100\%); (i) date of the medico-legal consolidation of the injuries $(100 \%)$; $(j)$ parameters of temporary harm $(100 \%) ;(k)$ parameters of permanent harm (93.3\%). Such results means that in a very high number of cases, the forensic experts merely give direct answers to the questions posted to them. This fact demands deep reflection in the sense of finding a way to change the procedures of this matter given the relevance of the issues involved.

Key-words: Bodily harm; Road traffic accident; Forensic evaluation; Medical expertise; Civil Law; Reparation.

Résumé: Évaluation du dommage corporel au Brésil. Le cas des accidents de route Au Brésil il n’y a pas une norme spécifique pour l'évaluation des dommages corporelles post-traumatiques en droit commun. Dans la plupart des instituts de médecine légale le modèle du droit pénal est suivi, et même la table officielle d'invalidité et d'autres directives et législation en vigueur ne sont généralement pas utilisées. Cela ne bénéficie pas de la qualité des évaluations et est certainement préjudiciable à une bonne administration de la justice. Ainsi, cette étude vise à analyser du point de vue médico-légal et juridique la méthodologie de l'évaluation des dommages corporelles de victimes d'accidents de la circulation au Brésil et, à partir des résultats, réfléchir sur les procédures adoptées dans ce méthodologie, ayant comme éléments de comparaison le modèle en usage à l'Institut national de médecine légale, IP, Portugal. Une étude observationnelle a été réalisée avec un élément analytique, qui se consistait d'une analyse des rapports médico-légaux de l'IML préparés à Belo Horizonte, relatives aux accidents de routes $(n=254)$. Les rapports omettent les sujets: (a) des renseignements sur la victime comme l'âge et l'état matrimonial (3,1\% et $8,3 \%$ respectivement), (b) des antécédents de maladie et de traumatisme de la victime $(100 \%)$ (c) date de l'accident $(86,6 \%)$, (d) la carac- 
térisation de l'accident $(81,9 \%)$, (e) de référence au type de véhicule impliqué $(68,5 \%)$, (f) l'emplacement et le type de blessures $(20,5 \%$ et $31,9 \%$, respectivement) ( $\mathrm{g}$ ) des séquelles physiques, fonctionnelles et situationnelles $(3,1 \%, 9,1 \%$ et $79,5 \%$ respectivement), (h) un lien de causalité entre le traumatisme et les dommages (100\%) (i) la date de la consolidation médico-légale des lésions (100\%), (j) les paramètres des dommages temporaires (100\%) (k) les paramètres de dommages permanents $(93,3 \%)$.Cela signifie que dans un grand nombre de cas, les experts se limitent à donner seulement la réponses directes à des questions. Cela demande une profonde réflexion afin de trouver un moyen de changer les procédures dans ce sujet, étant donné la pertinence des questions soulevées.

Mots-clés: Dommage corporel; Accident de circulation; Évaluation médico-légale; Expertise médicale; Droit civil; Indemnisation.

\section{Agradecimentos}

Ao Dr. João Batista, Diretor de Perícias do Instituto Médico-Legal de Belo Horizonte e ao Dr. Gustavo Botelho, Superintendente Geral da Polícia Civil de Minas Gerais.

\section{Pedido de separatas:}

WAGNER SILVA

wagnersilva@imep.com.br 